\title{
Balancing basic and applied research outputs: A study of the trade-offs between publishing and patenting
}

\author{
Jasmina Berbegal-Mirabent* \\ Department of Economy and Business Organization, Universitat Internacional de Catalunya \\ C/ Immaculada 22, 08017, Barcelona, Spain \\ Email: jberbegal@uic.es \\ *Corresponding author
}

Ferran Sabate

Department of Management, UPC • BarcelonaTech

C/ Jordi Girona, 31, 08036, Barcelona, Spain

Email: ferran.sabate@upc.edu 


\title{
Balancing basic and applied research outputs: A study of the trade-offs between publishing and patenting
}

\author{
This study examines the relationship between academic publications and patents. First, \\ we use regression models to investigate those factors that act as potential drivers when \\ considering papers and patents individually. Second, we run a cluster analysis in order \\ to test whether universities follow different patterns in the way they align their \\ resources in regard to research objectives. The empirical application considers the \\ Spanish public higher education system for the period 2006-10. The overarching \\ conclusion is that cross-fertilisation relationships between academic research and its \\ commercialisation are found. There are, however, important differences on how \\ universities are disseminating research results when we in-depth in the analysis of the \\ resources and capabilities universities possess. Results also stress the need to look at \\ contextual and normative factors.
}

Keywords: Linkages between science base \& commercialization, Public research organisations, Patents, Publications, University, Quantitative 


\section{Balancing basic and applied research outputs: A study of the trade-offs between publishing and patenting}

\section{Introduction}

In a context where the intensity and the quality of university-industry links is assumed to generate technological spillovers and determine effective returns on investment in research, bridging the gap between science and industry has become a major concern for academics, managers and policy makers (Lai 2011). A number of initiatives and regulatory frameworks have been established aiming at involving scientists in commercialisation activities and facilitating the usage and exploitation of scientific discoveries through appropriate property rights protection mechanisms. One example is the passage of the Bayh-Dole Act in 1980 in the US and other similar favourable regulatory environments. The result is a natural increase in the number of patents granted to universities (Czarnitzki, Glanzel, and Hussinger 2007).

Patents are commonly seen as playing a major role in markets for intellectual property, facilitating the disclosure of technical information. Although they do not guarantee the future marketability of the technology, they represent a key tool for safeguarding their potential. However, some observers are slightly sceptical about the long-term consequences that commercialisation activities may have over publications and the academic culture of open science (Geuna and Nesta 2006). Similarly, doubts emerge about a potential shift in the 
traditional incentives of researchers to engage in basic and applied research activities (Van Looy, Callaert, and Debackere 2006).

This study is intended to shed some light on this debate. By means of an empirical analysis we test the hypotheses of complimentary versus rivalry relationships between basic (publications) and applied (patents) scientific achievements in academia. The sample considers the Spanish higher education system for the period 2006-10.

Academic scientists build their careers mainly upon reputation and accreditation systems. According to the Spanish National Agency of Quality Assessment and Accreditation Trust (ANECA), the most valued criterion for being designated for any of the different types of academic positions is papers published. The weights in the final evaluation range between $26-35 \%$ for publications, and 3-12\% for patents, according to the knowledge field. Moreover, the novelty requirements imposed by intellectual property rights (IPR) laws entail publication restrictions. This means that academic inventors are usually asked to keep their research secret until the patent application has been filed, resulting in publication delays. These facts suggest that the reputational reward system of patents may be slightly different from the publishing one. Yet, such incentives may be relaxed once the promotion is awarded. Publications also tend to be more valued than patents when evaluating universities. For instance, in the Academic Ranking of World Universities, $20 \%$ of the total score is based on the number of papers published. Similarly, in the QS World University Ranking the same 
percentage is given to citations per faculty. On the contrary, none of these two rankings considers patents.

These records suggest that there is both an internal pressure (at the individual level of the researcher, to advance in his/her academic career) and an external one (at the aggregate level of the university, to achieve a better position in rankings) to publish more and better, rather than to disseminate research results through patents.

In order to investigate the extent to which academic patenting is compatible with publication activities a two-step analysis is proposed. First, we investigate, through different regression models, those factors that act as drivers when considering papers and patents independently. Second, based on a cluster analysis, we examine the conditions under which these two outputs coexist. Conclusions and policy implications are discussed.

\section{Literature review}

A growing number of studies are examining the combined effects that publications and the inventorship of patents have. Three effects are observed as follows.

\subsection{No effect}

A first bunch of studies shows that the adoption of an applied research orientation is not at the expense of publications. Using a large sample of active professors in Germany, Czarnitzki, Glanzel, and Hussinger (2007) provide empirical evidence that commercialising 
academic discoveries has no negative implications on publication counts. Similarly, Agrawal and Henderson (2002) and Gulbrandsen and Smeby (2005) conclude that patenting activity does not appear to be dependent on publishing activity.

The motives for patenting seem to play a key role. Choosing patenting over publishing may be related with a tenured position (not needing further academic credentials for promotion). This links with the idea that individual incentives gradually change over time (Calderini, Franzoni, and Vezzulli 2007).

This no empirical evidence for a negative impact seems to support the idea that substitution and reinforcement effects are blended. Therefore, unidirectional forces driving university publications and patents are counteracted.

\subsection{Positive effect}

A greater faculty involvement in industry can also lead to increased levels of basic research outcomes. In order to test the 'co-activity' of science and technology, Meyer (2006) found that, in nano-science and nano-technology fields, co-active researchers outperform their colleagues. Similarly, Stephan et al. (2002) studied this relationship at the individual level, and found that the probability to apply for a patent is related to previous experience in publishing. Likewise, Carayol and Matt (2004) found that highly publishing labs were also active in patenting. Going a step further, Klitkou and Gulbrandsen (2010) observed that differences among fields, the university profile and other contextual factors also play a role in 
the effects of patenting.

Recent studies are questioning the direction of this reinforcement effect (Carayol and Matt 2004): is patenting opening up new scientific opportunities that lead to publications, or is patenting preceded by publications? Although the answer is still unclear these studies corroborate that, at least in some disciplines, university-industry links are enriching, strengthening the idea that patents are by-products of scientific work rather than substitutes (Breschi, Lissoni, and Montobbio 2007; Murray 2002).

\subsection{Negative effect}

A third stream of studies argues that patenting suppresses scientific publishing and vice versa. Rizzo and Ramaciotti (2014) found a negative but low significant effect, signalling that the scientific productivity of a university does not influence its propensity to apply for patents.

This substitution effect is explained by the difficulties and the time required for transferring scientific discoveries into marketable creations (Thursby and Thursby 2002).

There are many norms of secrecy and interdictions that prevent researchers to share research materials and disseminate the discoveries through publications before the patenting opportunity has not been sorted out (Geuna and Nesta 2006). Furthermore, patenting is a time-consuming task that implies a significant reduction in the time devoted to publishing activities (Klitkou and Gulbrandsen 2010). In addition, not many researchers patent and those that do it, do it rarely. Thus, a lack of practice may also support this substitution effect. 


\section{Hypotheses}

Following Del-Palacio, Sole, and Berbegal (2011), we assess the explanatory power that universities' internal services have over publications and patents.

\subsection{Human capital}

The presence of high levels of human capital influences the quality of business behaviour (Becker 1975). This is especially relevant in universities, organisations that heavily rely on individual's knowledge and capacities (Benneworth and Hospers 2007).

The first dimension of human capital considered refers to the direct labour force

[DLF], that is, those faculty members engaged in research activities. Academic staff constitutes a unique resource for universities, as they are the first frontline in command of the academic and research activities. This way we hypothesise that:

Hypothesis 1: The highest the proportion of faculty members highly involved in research activities, the greatest the research outcomes (in terms of patents and publications).

The second dimension relates to the personnel involved in specific support tasks such as administrative or service oriented activities but that are crucial for supporting researchers' daily activities (Kusku 2003). Support labour force [SLF] includes library and research support staff. As for the specific case of patenting, this activity requires coaching and an appropriate assessment, thus, it becomes necessary to consider the technical staff devoted to IPR. From here we hypothesise that: 
Hypothesis 2: There is a positive relationship between the access to support labour force and the level of research outcomes (publications and patents).

\subsection{Experience}

Accumulated knowledge [KA] provides individuals with the specific know-how and capabilities which can help them develop more successful strategies, and consequently, potentially achieve higher outcome rates. This dimension aims at capturing the dynamic knowledge spillovers derived from past experience which may help create a more fertile setting for the development of new activities (Ploeg and Veugelers 2008). In this sense, we consider that the presence of knowledge stock or background that faculty and the institution have in a specific field can help universities in obtaining new outputs. Accordingly, we hypothesise that:

Hypothesis 3: Knowledge accumulation is positively related to new research outcomes (publications and patents).

Another way to account for the experience is measuring how actively the university has been involved in producing the desired outputs. Moreover, following Gueno (1998) and Merton (1988) old universities can have both a halo and a Mathew effect based on historic interactions of expertise and prestige. This translates in saying that those universities with seniority [S] are likely to have developed appropriate policies, managerial capabilities and 
infrastructures that facilitate the production of the desired outputs. Consequently, we hypothesise that:

Hypothesis 4: There is a positive relation between seniority and the achievement of higher levels of outcomes (publications and patents).

\subsection{Financial resources}

Previous research reports a positive relation between access to financial resources and knowledge transfer activities (Landry, Amara, and Ouimet 2007). Income from R\&D activities is considered an appropriate proxy for university's financial resources as it represents the monetary income from the exploitation of research results (Cohn, Rhine, and Santos 1989). This income may be seen as that derived from specific fundraising universitiesindustry partnerships or that coming from the commercialization of specific research outcomes. Given that financial resources are critical for developing new research activities, we hypothesise:

Hypothesis 5: There is a positive relationship between universities' income from previous $R \& D$ activities and the level of research outcomes (publications and patents).

Technology transfer activities are also supported by specific units, known as technology transfer offices (TTOs). These units act as knowledge brokers (BerbegalMirabent, Sabate, and Cañabate 2012) linking university discoveries with practical application with industry's needs. Because knowledge commercialization is possible due to 
previous investment in research, the commercialization of the results is likely to be influenced by the amount of funding available at TTOs. As a result, we hypothesise that: Hypothesis 6: There is a positive relationship between the budget of the TTO and the number of patents.

\subsection{Profile}

This dimension captures the university's academic diversification and the orientation of the research engaged. Previous research indicates that universities either with medical schools or more oriented towards engineering studies are more likely to generate higher levels of research outcomes with a clear market orientation than those universities with a greater orientation in social science or humanities (Landry, Amara, and Ouimet 2007). In terms of publications, a similar behaviour is observed. In some knowledge fields it is easier for academics to develop their research activities and publish in scientific journals than in other fields. For instance, according to the Spanish ANECA, for being considered as a full professor, researchers are expected to have published in the last 10 years between 16 and 40 papers, according to the knowledge field. Based on this rationale, we hypothesise that:

Hypothesis 7: Polytechnic universities are more prone to achieve higher levels of research outcomes (publications and patents). Hypothesis 8: Universities with medical schools are more prone to achieve higher levels of research outcomes (publications and patents). 
Finally, concerning the intrinsic characteristics of universities, we take into account university size. Empirical studies have found that university size is positively related to the amount of knowledge transferred (Belenzon and Schankerman 2009). Based on this argument, we hypothesise that:

Hypothesis 9: Larger universities will be linked to higher rates of research outcomes (publications and patents).

\subsection{Patterns followed by universities}

Universities face multi-dimensional objectives (teaching, research and technology transfer) and align their internal resources and capabilities according to their strategic vision. In this line, previous studies suggest that universities behave differently, and thus, follow different patterns in the way they shape their strategies with their objective function (Berbegal-

Mirabent, Lafuente, and Solé 2013).

Moreover, universities are somehow embedded in their regional context; consequently, the exposure to specific regional economic variables may influence universities' capacity to achieve high performance rates (Shattock 2009), especially in terms of research productivity. Accordingly, we hypothesise:

Hypothesis 10: Spanish public universities follow different pathways in relation to the strategy adopted to address the research objective mission. 


\section{Data and method}

\subsection{Data}

We focus on the Spanish case, using data from all presence-based public universities of the country (47) for the period 2006-10, included in the reports of the Council of Rectors of Spanish Universities (CRUE) and the Spanish Network of Technology Transfer Offices (RedOTRI).

\subsection{Variables}

Two dependent variables are used: the number of papers published in journals indexed in the ISI-Web of Knowledge in 2010, and the number of patents granted in 2010 by the Spanish Patent and Trademark Office (OEPM).

Direct labour force has traditionally been measured by total number or full-time equivalent faculty staff (Archibald and Feldman 2008), or by categorising research staff according to the position they hold (Caballero et al. 2004). We use this latter approach, and consider the percentage of academic staff holding a $\mathrm{PhD}$, a quality criterion which is expected to be linked to a greater academic productivity in terms of publications. To quantify the direct labour force that will be likely to patent, prior patenting involvement of researchers is commonly used (Czarnitzki, Hussinger, and Schneider 2011). Accordingly, we use the percentage of faculty members involved in knowledge transfer activities. As for the staff 
supporting researcher's activity, similar to previous studies (Caldera and Debande 2010; del-

Palacio, Solé, and Berbegal 2011) we use library staff relative to total support staff, and research support staff relative to total support staff for the model predicting the number of publications. In the patents model we us specialised employees in IPR tasks relative to the total number of employees working in the TTO.

Knowledge accumulation employs two measures. For the model explaining papers, we use the percentage of papers published in the first quartile of ISI-Web of Knowledge ranked journals in the last two years. As for the model predicting patents we calculate the effectiveness ratio of patents emerging from invention disclosures. In both cases measures aim at capturing not only the knowledge spillovers derived from past experience but the quality of the prior activity. The second dimension of experience, seniority, is captured using the number of years that both the university and the TTO have been in operation (Conti and Gaule 2011).

To assess financial resources we use the income coming from R\&D activities, and the budget of the TTO (Berbegal-Mirabent, Sabate, and Cañabate 2012). According to the RedOTRI, for the period under analysis over $76 \%$ of the budget of Spanish TTOs comes from their parent university, public grants and overheads. This means that the rents resulting from the commercialization of the knowledge and technology are unfortunately still low. 
Accordingly, it makes sense hypothesising that those TTOs with larger budgets would have more opportunities to invest resources in the valorisation of their research outcomes.

Size effects are also controlled. The literature suggests different ways for taking it into account. One option considers the amount of people working (faculty members) or studying (students) in the organisation (Muscio 2010). An alternative approach account for the availability of infrastructures and spaces (e.g. seats in classrooms, laboratories, total area) (Agasisti and Dal-Bianco 2009; Kao and Hung 2008). Following this latter approach, we take university total area in thousands of square meters.

Finally, concerning the nature of the research engaged, previous studies looked at the presence of specific hard-science schools (e.g. medicine or engineering), or considered the diversity of the portfolio of studies offered (Conti and Gaule 2011). In this paper we use two dummy variables: whether the university offers medical studies, and if the university is a polytechnic university.

\subsection{First stage analysis}

First stage assesses the explanatory power that universities' internal services have over scientific productivity. The linear regression is the econometric technique chosen to assess the number of publications (Model 1). A negative binomial regression method is used for the patents model (Model 2) due to the highly skewed distribution of the dependent variable (Greene 2008). 
Some considerations are in order. First, to control for potential endogeneity problems

explanatory variables were introduced as lagged terms and the values of these variables

correspond to those reported for the year 2008/09. Second, to ensure the robustness of the

significance of the results on the full model, we also examined the explanatory power that

each exogenous variable has over the corresponding research output in an individual fashion.

Results validate the consistency of both full models. Third, some variables were transformed

by use of the natural logarithm (R\&D income, TTO budget, university size, university age

and TTO age) to obtain normality. Fourth, normal probability plots of the residuals for Model

1 corroborate that they were normally distributed. Fifth, no collinearity problems were

observed, as the maximum VIF calculated was 4.17 (Rogerson 2001). Sixth, due to the lack

of information on certain explanatory variables six universities have been dropped out from

the final sample for Model 2.

\subsection{Second stage analysis}

We first analyse the relationship between patents and publications considering the whole set of Spanish public universities. Missing values in the number of patents were linearly estimated by means of the least square method. Only one university (Universidad de Salamanca) was dropped from the final sample due to insufficient data.

Second, based on the hypothesis that Spanish public universities follow different behavioural patterns in the allocation of internal resources, we propose a non-hierarchical 
cluster analysis (K-means) using the variables that are found to be significant in stage one. As the number of clusters must be specified prior the estimation, two approaches are used to validate the number of clusters: we computed the Calinski and Harabasz (1974) statistic, being four the number of clusters that maximises the $C H(k)$ index (pseudo- $F$ value=79.930); then, we ran a discriminant analysis to further corroborate that our approach was appropriate. The lack of information on certain explanatory variables (TTO budget) leads us to drop five universities from the final sample.

\section{Empirical results and discussion}

\subsection{Forces driving academic research outputs}

Table 1 presents the results. As for the direct labour force dimension, results indicate that the proportion of faculty members holding a $\mathrm{PhD}$ does not help explaining publications. A similar behaviour is found in Model 2 for the proportion of faculty members involved in knowledge transfer (KT) activities. To further examine this finding we correlate these two variables with their respective dependent variables. Additional descriptives corroborate that holding a $\mathrm{PhD}$ is linked to a greater academic productivity in terms of publications $(42.8 \%$, $\mathrm{p}$ value $=0.003$ ), whereas the proportion of faculty members involved in KT activities is not statistically significant $(-16.7 \%$, p-value $>0.100)$. This lack of significance can be explained by the conditions that dominate the research landscape in Spain, where incentive schemes 
play a decisive role.

$<$ Insert_Table1_about_here $>$

Considering the support labour force dimension, we found that due to the complexity

of the legal aspects and/or because researchers are not used to patent, those universities with a

higher proportion of TTO staff devoted to IPR tasks are more prone to achieve better

performance rates in terms of patents. Therefore, specialised assessment and coaching are

desired services when patenting. However, this positive and significant effect diminishes in

Model 1, indicating that publishing mainly relies on researchers' capabilities and that this

process is commonly well-known for academics.

Knowledge accumulated helps people develop their tasks more efficiently. In Model 1

previous publishing activity in highly qualified journals is positively related with new

publications, pointing out to dynamic knowledge spillovers derived from past experience.

This hypothesis is not supported in Model 2. However, if we analyse the correlation between patents granted in 2010 and those for the period 2007-9, there is a positive and significant correlation $(80.1 \%$, p-value $<0.010)$. Nonetheless, the mechanisms that should facilitate efficient conversion rates have not yet been fully implemented.

The seniority effect is significant in both models. While the age of the university is a determinant factor for publishing, the age of the TTO positively influences the patenting activity, signalling a potential relationship between seniority and reputation. 
Access to financial resources is also crucial. The income generated from prior $R \& D$ activities represents an economic cushion that boosts new research activities which may turn into publications. Although this effect weakens in Model 2, a strong correlation is observed between $R \& D$ income and the number of patents $(65.34$, p-value $<0.010 \%)$. Results also confirm that those TTOs with higher annual budgets generate more patents.

The effect of the profile of the university over research outcomes is also evidenced. Polytechnic universities and those with medical studies outperform their peers in the number of patents; however, there are no differences in terms of publications.

Finally, size also plays a role. While there is no doubt of its significance in Model 2 $(p$-value $=0.009)$, some interrogations arise in Model $1(p$-value $=0.103)$. Nevertheless, when the standard errors for Model 1 are based on the observed information matrix instead of robust, this variables turns out to be statistically significant ( $p$-value $=0.069$ ). Accordingly, we posit that large universities have a greater capacity to create economies of scale and produce research outputs.

\subsection{Publishing versus patenting activities}

Spanish public universities have substantially increased their research activity for the 200610 period. While the total number of publications has increased by $136.7 \%$, the number of patents granted has almost duplicated (179.6\%). This double intensification suggests a potential reinforcement effect between publishing and patenting. 
In order to better understand the underlying rationale of this relationship we first correlate the accumulated number of papers and patents for the last 5 years. A positive and statistically significant effect is observed ( $\mathrm{p}$-value $=0.009$ ), signalling a slightly lineal relationship between both variables $\left(\mathrm{R}^{2}=0.163\right)$ (Figure 1$)$. Thus, our preliminary results are not conclusive to support the hypothesis of reinforcement effects.

$<$ Insert_Figure_1_about_here $>$

Because universities face multi-dimensional objectives and shape their research activities following different strategies, these results should be taken with a grain of salt. To further investigate the ways through which Spanish universities align their resources with regard to research outputs, we ran a cluster analysis. Table 2 presents the results. Four different groups are observed, confirming H10 which states that Spanish universities follow different pathways in relation to the strategy adopted to address the research objective mission.

$<$ Insert_Table2_about_here $>$

Universities in cluster $\mathbf{1}$ do not seem to excel in any of the performance variables. Yet, their results are much better in publishing than in patenting. These universities published on average 3,139 for the period 2006-10 (766.75 in 2010), and 21.500 patents were granted for the same period (6.750 in 2010). Although these universities are large institutions, have on average 178.000 years of experience, and offer medical studies, their low performing rates 
are explained by a resource shortage, both in financial terms and human capital (except for the proportion of faculty members holding a $\mathrm{PhD}$ ).

In this group, Universidad de Zaragoza (UZA) is an influential point since its Cook's distance is above the convention cut-off point of $4 / \mathrm{n}(1.125>1)$. Particularly, UZA doubles the average number of papers published in 2010 by the other three universities in this group $(1,190$; average: 766.75). A similar behaviour is observed in the accumulated number of patents (period 2006-10), where UZA is first ranked with 44 patents, far ahead from University of Córdoba, with 22 patents. The overreaching conclusion is that although universities in group 1 have a comparable level of resources, certain universities have created an enabling atmosphere for the development of university-industry alliances with no damaging effect on traditional research outcomes.

Universities in cluster $\mathbf{2}$ are more oriented towards disseminating new knowledge through publications, however, they show both the lowest concentration of papers (average number of papers: $1,814.048)$ and patents (17.143) for the period 2006-10, explained by a weak previous experience in publishing and patenting. Universities in this group are lacking an enabling environment. They have important constraints in terms of financial resources and human resources are also scarce. Even though these universities better excel in disseminating knowledge through publications, there is no substitution effect but a lack of a culture aimed at safeguarding research results for future commercialisation and exploitation activities. 
According to Cook's distance rule of thumb, cluster 2 has two influential

observations: Universidad de Cádiz (UCA) and Universidad de Vigo (UVI). Within

universities in this cluster and for the period 2006-10, UCA exhibits the highest production of

patents (45; average: 17.143$)$, while UVI shows the highest production of papers $(3,534$;

average: 1814.048$)$.

Universities in cluster 3 stand out for their experience in the market. Despite their relative youth (average: 36.890 years), they possess senior TTOs (second ranked). Other shared features include size (large universities), an important stock of human resources and the access to financial resources. Because this cluster comprises universities offering studies in medicine and three out of the four Spanish polytechnic universities, this group reports the highest figures in patents. Additionally, publication numbers are also above the average. These results corroborate that specialised universities have a greater capacity to accumulate knowledge which accelerates researcher's activity in form of publications and marketable inventions.

In this group Universitat Autònoma de Barcelona (UAB) clearly outperforms in terms of publications $(9,479$; average: $5,046.444)$ being to some extent this basic research orientation counterproductive for transferring knowledge through patents (14; average: 56.333). From the statistical point of view, UAB is an influential observation (Cook's distance rule of thumb: 0.682>4/9). Although Figure 2 seems to indicate a slightly negative 
relationship between publications and patents, an in-depth analysis reveals that universities in cluster 3 are taking advantage of the natural spillovers that arise from a close relationship with the industry sector. Accordingly, they base their strategy on their capacity to transform their different resources, previous experience and academic specialisation to strengthen university-industry collaborations which may turn into new knowledge that will be disseminated through different mechanisms. Therefore, patenting and publishing are important objectives to be accomplished simultaneously.

$<$ Insert_Figure_2_about_here $>$

For the period under analysis, the average number of publications and patents for universities in cluster 4 (papers: 7,663.143; patents: 44) is relatively high compared to that of Spanish public universities (papers: 3,651.488; patents: 30.756). Universities in this group seem to base their strategy in disseminating new knowledge through publications.

Nevertheless, their publication intensity seems to be slightly negatively correlated with the patenting activity despite its non-statistical significant effect ( $p$-value=0.911) (Figure 2), indicating that although possessing the resources, these universities leave aside the possibility to translate research results into something valued by the market. This path suggests that academics perceive no or few motivations to engage in commercialisation activities. Consequently, universities from this group should define specific incentives to create an enabling environment for transferring academic research. 
Within this group Universidad de Valladolid (UVA) acts as an influential point

(Cook's distance: 1.199>0.571; studentized residual: -2.794$)$. Compared to universities in cluster 4, UVA exhibits the lowest performance rates in terms of publications (590) and patents granted in 2010 (11), a trend that is also observed when considering the accumulated number of papers and patents for the last 5 years (papers: 2,790; patents: 19). In terms of research outcomes, this university seems to fit better with those in cluster 1; however access to financial resources is much in line with those universities in cluster 4.

\section{Conclusions and policy implications}

Universities are seeking for additional sources of rents and reputation, but they certainly do not want to do this so if these activities are in detriment of traditional research activities. In this context, the analysis of the trade-offs between publications and patents is paramount. Throughout this study we have brought further insights on this specific topic by focusing on the Spanish public university sector. We first embarked on the analysis of the determinants of papers and patents in an individual fashion. As for the key results, we found that TTO staff involved in IPR activities helps explain the number of patents. Both knowledge accumulation and seniority positively influence publishing activities, while this effect dilutes when patenting is the main objective. The access to financial resources is also decisive, especially R\&D income for publishing and the budget of the TTO for patenting. This latter result should be interpreted with caution, because larger TTOs may lead to a 
greater activity in terms of knowledge flow, without this availability of results being necessarily translated into higher investments in patent activity. Lastly, we found that the profile of the university is a key determinant, particularly when patenting. Size effects are also observed.

Second, we empirically assessed how universities allocate their resources when simultaneously dealing with publishing and patenting objectives. Our results indicate that, for the whole set of Spanish public universities, patents and papers are positively correlated, indicating complementary effects. To get a better grasp on how universities behave, we conduct a cluster analysis, and identify four different patterns. Universities in clusters 1 and 2 exhibit acceptable levels of publication outcomes, but a resource shortage and a lack of a culture aimed at safeguarding research results diminish their capacity to transfer scientific discoveries into marketable products. In terms of policy making these universities should enhance the interconnectivity of the different university's structures, while reinforcing the linkages with the industry. Universities in clusters 3 and 4 outperform their peers in terms of publications and patents. While for universities in cluster 3 patenting and publishing objectives seem to coexist without damaging effects, universities in cluster 4 mainly drive their research efforts on behalf of publications, an orientation that, to some extent, implies sacrificing the patenting activity. 
The aforementioned results seem to corroborate those contributions that suggest that

publications and patents can be obtained simultaneously. Nevertheless, universities are carrying out basic and research activities at different levels of commitment, which clearly depend on structural, normative and cultural factors. These differences materialises in multiple ways of addressing their research objective mission, complicating any effort to converge on a homogenous policy design.

In terms of policy making, universities should define specific incentives that create a favourable environment for the valorisation of academic research. Potential extraordinary revenues, new research opportunities or the creation of scientific networks are some initiatives that can both motivate institutions and their faculty members.

The global economic downturn has strongly hampered the Spanish higher education system, which is suffering from its begging (2008-2009) an important resource shortage. This scarcity in the resources may have affected the performance of universities in their research activities. We believe this question to be of great interest. Future studies should consider this analysis and determine whether the different pathways identified are maintained over time.

The main limitation of this study relates to the specific analysis of the Spanish public higher education system. Nevertheless, other countries can benefit from this research. First, trade-offs between publishing and patenting are not specific of the Spanish higher education system. Several factors such as public-private expenditures on R\&D (Botta 2014), 
governance models (Dobbins, Knill, and Vögtle 2011), and university autonomy (Moscatti 2012), suggest similarities with higher education systems in Italy, Portugal and France. Second, normative, social and cultural heritage generates different ways of operating. Accordingly, further research efforts should be directed towards analysing the extent to which the geographical dimension is influencing academic research.

New research avenues should compare how public and private universities perform, and determine whether the presence of shareholder-driven objectives and different financial structures affect university performance. However, the lack of a homogenous disclosure policy for public and private universities prevents us to undertake this comparison.

Finally, it is important to remark that data available are rich and reliable variables were created. However, future studies might consider the use of complementary indicators that make possible to evaluate, to a greater extent, the quality of the outcomes produced.

\section{References}

Agasisti, T., and A. Dal Bianco. 2009. Reforming the university sector: effects on teaching efficiency - evidence from Italy. Higher Education 57: 477-98. doi: 10.1007/s10734$\underline{008-9157-\mathrm{x}}$.

Agrawal, A., and R. Henderson. 2002. Putting patents in context: exploring knowledge transfer from MIT. Management Science 48: 44-60. doi:10.1287/mnsc.48.1.44.14279.

Archibald, R.B., and D.H. Feldman. 2008. Graduation rates and accountability: Regressions versus production frontiers. Research in Higher Education 49: 80-100. doi:10.1007/s11162-007-9063-6. 
Azagra-Caro, J.M., F. Archontakis, and A. Yegros-Yegros. 2007. In which regions do universities patent and publish more? Scientometrics 70: 251-66. doi:10.1007/s11192-007-0202-9.

Becker, G. 1975. Human capital. Chicago: University of Chicago Press.

Belenzon, S., and M. Schankerman. 2009. University knowledge transfer: private ownership, incentives, and local development objectives. The Journal of Law and Economics 52: $111-44$.

Benneworth, P., and G. Hospers. 2007. Urban competitiveness in the knowledge economy: universities as new planning animateurs. Progress in Planning 67: 105-97.

Berbegal-Mirabent, J., E. Lafuente, and F. Solé. 2013. The pursuit of knowledge transfer activities: an efficiency analysis of Spanish universities. Journal of Business Research, 66: 2051-59. doi:10.1016/j.jbusres.2013.02.031.

Berbegal-Mirabent, J., F. Sabate, and A. Cañabate. 2012. Brokering knowledge from universities to the marketplace: the role of knowledge transfer offices. Management Decision 50: 1285-307. doi:10.1108/00251741211247012.

Botta, A. 2014. Structural Asymmetries at the Roots of the Eurozone Crisis: What's New for Industrial Policy in the EU? SSRN Scholarly Paper ID 2508164. Rochester, NY: Social Science Research Network. http://papers.ssrn.com/abstract=2508164.

Breschi, S., F. Lissoni, and F. Montobbio. 2007. The scientific productivity of academic inventors: new evidence from Italian data. Economics of Innovation and New Technology 16: 101-18. doi:10.1080/10438590600982830.

Caballero, R., T. Galache, T. Gómez, J. Molina, and A. Torrico. 2004. Budgetary allocations and efficiency in the human resources policy of a university following multiple criteria. Economics of Education Review 23: 67-74. doi:10.1016/S0272$\underline{7757(03) 00049-9 .}$. 
Caldera, A., and O. Debande. 2010. Performance of Spanish universities in technology transfer: an empirical analysis. Research Policy 39: 1160-73. doi:10.1016/j.respol.2010.05.016.

Calderini, M., C. Franzoni, and A. Vezzulli. 2007. If star scientists do not patent: the effect of productivity, basicness and impact on the decision to patent in the academic world. Research Policy 36: 303-19.

Calinski, T., and J. Harabasz. 1974. A dendrite method for cluster analysis. Communications in Statistics - Theory and Methods 3: 1-27. doi:10.1080/03610927408827101.

Carayol, N., and M. Matt. 2004. Does research organization influence academic production? Laboratory level evidence from a large European university. Research Policy 33: 1081-102. doi:10.1016/j.respol.2004.03.004.

Cohn, E., Sherrie L.W. Rhine, and M.C. Santos. 1989. Institutions of higher education as multi-product firms: economies of scale and scope. The Review of Economics and Statistics 71: 284-90. doi:10.2307/1926974.

Conti, A., and P. Gaule. 2011. Is the US outperforming Europe in university technology licensing? A new perspective on the European Paradox. Research Policy 40: 123-35. doi:10.1016/j.respol.2010.10.007.

Czarnitzki, D., W. Glanzel, and K. Hussinger. 2007. Patent and publication activities of German professors: an empirical assessment of their co-activity. Research Evaluation 16: 311-9. doi:10.3152/095820207X254439.

Czarnitzki, D., K. Hussinger, and C. Schneider. 2011. Commercializing academic research: the quality of faculty patenting. Industrial and Corporate Change 20: 1403-37. doi:10.1093/icc/dtr034.

del-Palacio, I., F. Solé, and J. Berbegal. 2011. Which services support research activities at universities? Service Industries Journal 31: 39-58. doi:10.1080/02642069.2010.485194. 
Dobbins, M, C. Knill, and E.M. Vögtle. 2011. An analytical framework for the cross-country comparison of higher education governance. Higher Education 62: 665-83. doi:10.1007/s10734-011-9412-4.

Geuna, A. 1998. The internationalisation of European universities: a return to medieval roots. Minerva 36: 253-70. doi:10.1023/A:1004391922122.

Geuna, A., and L.J. Nesta. 2006. University patenting and its effects on academic research: the emerging European evidence. Research Policy 35: 790-807. doi:10.1016/j.respol.2006.04.005.

Greene, W. 2008. Functional forms for the negative binomial model for count data. Economics Letters 99: 585-90. doi:10.1016/j.econlet.2007.10.015.

Gulbrandsen, M., and J.C. Smeby. 2005. Industry funding and university professors' research performance. Research Policy 34: 932-50. doi:10.1016/j.respol.2005.05.004.

Kao, C., and H.T. Hung. 2008. Efficiency analysis of university departments: An empirical study. Omega 36: 653-64. doi:10.1016/j.omega.2006.02.003.

Klitkou, A., and M. Gulbrandsen. 2010. The relationship between academic patenting and scientific publishing in Norway. Scientometrics 82: 93-108. doi:10.1007/s11192-0090050-x.

Küskü, F. 2003. Employee satisfaction in higher education: the case of academic and administrative staff in Turkey. Career Development International 8: 347-56. doi: $10.1108 / 13620430310505304$.

Lai, W-H. 2011. Willingness-to-engage in technology transfer in industry-university collaborations. Journal of Business Research 64: 1218-23. doi:10.1016/j.jbusres.2011.06.026. 
Landry, R., N. Amara, and M. Ouimet. 2007. Determinants of knowledge transfer: evidence from Canadian university researchers in natural sciences and engineering. The Journal of Technology Transfer 32: 561-92. doi:10.1007/s10961-006-0017-5.

Merton, R.K. 1988. The Matthew effect in science, II: cumulative advantage and the symbolism of intellectual property. Isis 79: 606-23.

Meyer, M. 2006. Are patenting scientists the better scholars? An exploratory comparison of inventor-authors with their non-inventing peers in nano-science and technology. Research Policy 35: 1646-62. doi:10.1016/j.respol.2006.09.013.

Moscati, R. 2012. University Governance in Changing European Systems of Higher Education. In European Higher Education at the Crossroads, 599-611. Springer Netherlands. http://link.springer.com/chapter/10.1007/978-94-007-3937-6 32.

Murray, F. 2002. Innovation as co-evolution of scientific and technological networks: exploring tissue engineering. Research Policy 31: 1389-403. doi:10.1016/S00487333(02)00070-7.

Muscio, A. 2010. What drives the university use of technology transfer offices? Evidence from Italy. The Journal of Technology Transfer 35: 181-202. doi:10.1007/s10961$\underline{009-9121-7 .}$

Ploeg, F. van D., and R. Veugelers. 2008. Towards evidence-based reform of European universities. CESifo Economic Studies 54: 99-120. doi:10.1093/cesifo/ifn015.

Rizzo, U., and L. Ramaciotti. 2014. The determinants of academic patenting by Italian universities. Technology Analysis \& Strategic Management 26: 469-83. doi:10.1080/09537325.2014.882502.

Rogerson, P. 2001. Statistical methods for geography. London; Thousand Oaks, Calif.: SAGE Publications. 
Shattock, M. 2009. Entrepreneurialism in universities and the knowledge economy: diversification and organizational change in European higher education. Maidenhead: Open University Press.

Stephan, P.E., S. Gurmu, A.J. Sumell, and G. Black. 2002. Individual patenting and publication activity: having one's cake and eating it too. In Conference rethinking science policy: analytical frameworks for evidence-based policy, held on, 21-23. University of Sussex, Brighton, UK.

Thursby, J.G., and M.C. Thursby. 2002. Who is selling the ivory tower? Sources of growth in university licensing. Management Science 48: 90-104. doi:10.1287/mnsc.48.1.90.14271.

Van Looy, B., J. Callaert, and K. Debackere. 2006. Publication and patent behavior of academic researchers: conflicting, reinforcing or merely co-existing? Research Policy 35: 596-608. doi:10.1016/j.respol.2006.02.003. 
Figure 1. Scatterplot for the accumulated values of papers published and patents granted (2006-10) $48 \times 34 \mathrm{~mm}(600 \times 600 \mathrm{DPI})$

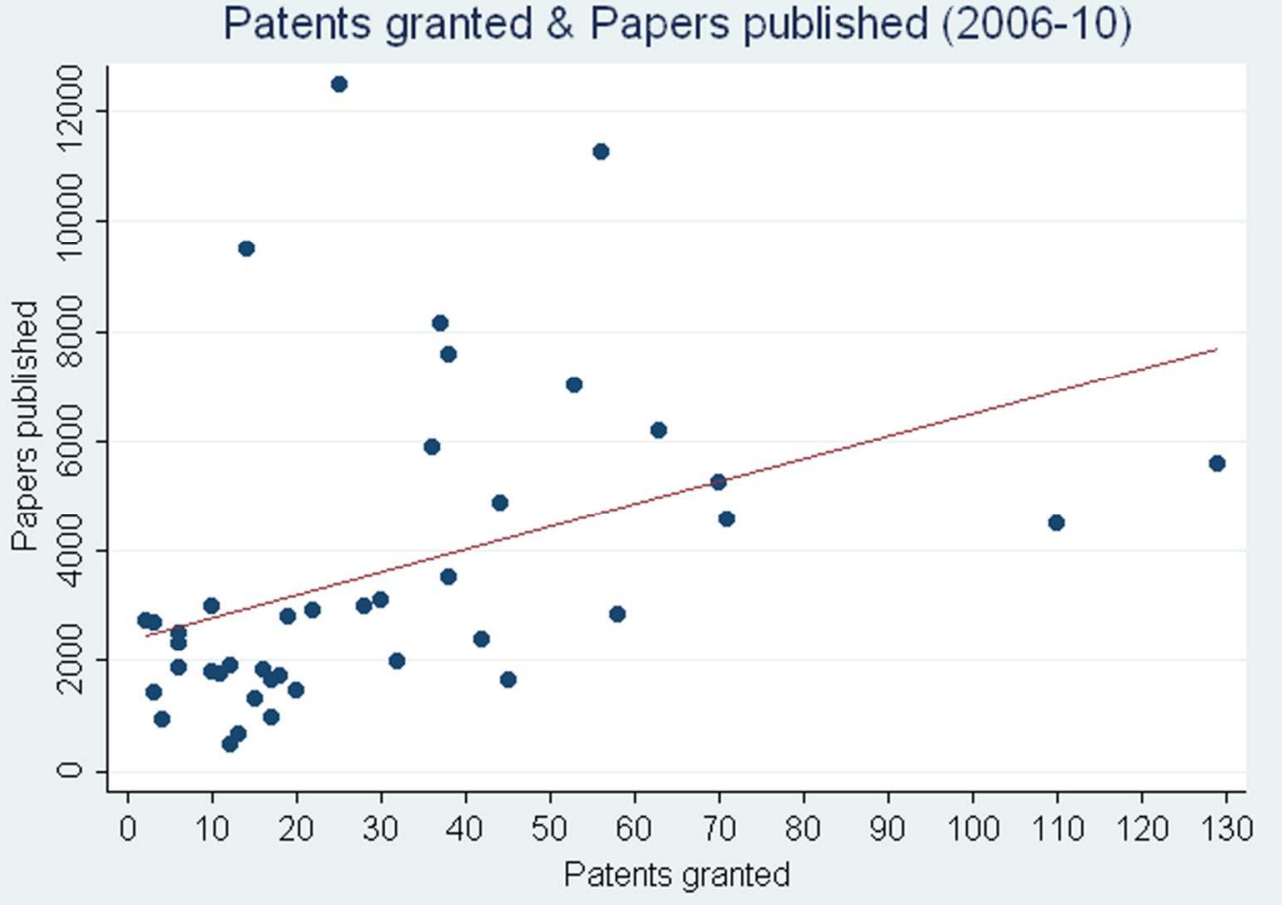


Figure 2. Scatterplot for the accumulated values of papers and patents (2006-10) by clusters $48 \times 34 \mathrm{~mm}(600 \times 600 \mathrm{DPI})$

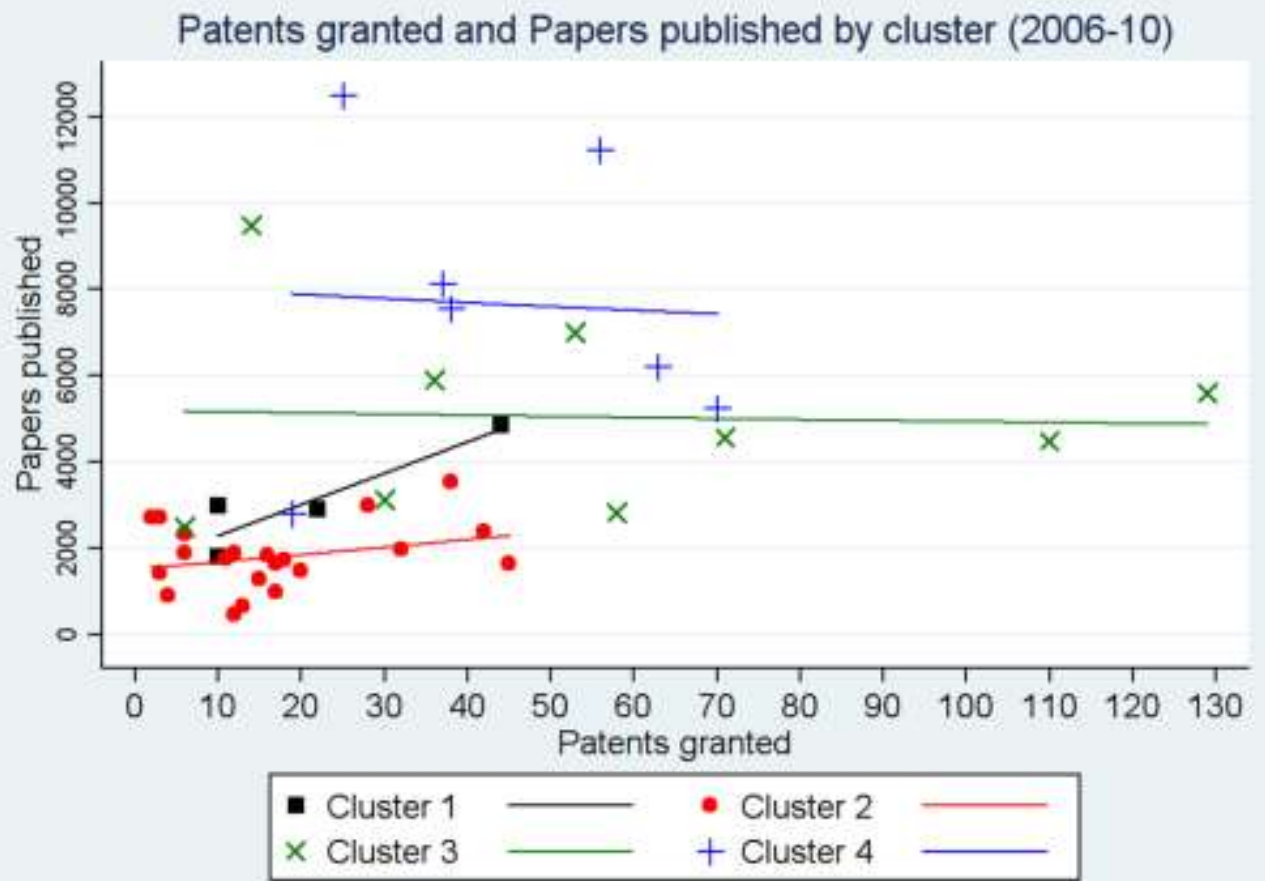

CTAS-2014-0183.R2 URL: http://mc.manuscriptcentral.com/ctas E-mail: profjamesfleck@icloud.com - FOR PEER REVIEW ONLY 
Table 1. Results of the regression analysis.

\begin{tabular}{|c|c|c|c|c|c|}
\hline \multirow{2}{*}{\multicolumn{2}{|c|}{ Factor }} & \multicolumn{2}{|c|}{ Model 1: Publications } & \multicolumn{2}{|c|}{ Model 2: Patents } \\
\hline & & Coefficient & Standard Error ${ }^{\mathrm{a}}$ & Coefficient & Standard Error ${ }^{\mathrm{a}}$ \\
\hline \multicolumn{6}{|c|}{ Human resources } \\
\hline \multirow{2}{*}[\mathrm{DLF}]{} & $\mathrm{PhD}$ faculty $(\%)$ & 0.618 & 0.458 & & \\
\hline & Faculty in KT activities (\%) & & & 0.553 & 0.887 \\
\hline \multirow{3}{*}[\mathrm{SLF}]{} & Library support staff (\%) & 0.560 & 1.205 & & \\
\hline & Research support staff (\%) & 0.713 & 0.464 & & \\
\hline & TTO staff in IPR tasks (\%) & & & $4.301^{* *}$ & 2.052 \\
\hline \multicolumn{6}{|c|}{ Experience } \\
\hline \multirow{2}{*}[\mathrm{KA}]{} & Papers Q1 (\%) & $2.223^{* *}$ & 1.090 & & \\
\hline & Patents/Invention disclosures & & & -0.297 & 0.427 \\
\hline \multirow{2}{*}{ [S] } & Age HEI & $0.086^{* *}$ & 0.042 & -0.094 & 0.058 \\
\hline & Age TTO & & & $0.925^{* *}$ & 0.432 \\
\hline \multicolumn{6}{|c|}{ Financial resources } \\
\hline \multicolumn{2}{|c|}{$\mathrm{R} \& \mathrm{D}$ income } & $0.503^{* * *}$ & 0.102 & 0.141 & 0.237 \\
\hline \multicolumn{2}{|c|}{ Budget TTO } & & & $0.047^{* *}$ & 0.021 \\
\hline \multicolumn{6}{|c|}{ Profile } \\
\hline \multicolumn{2}{|c|}{ Polytechnic university } & -0.200 & 0.132 & $1.063^{*}$ & 0.579 \\
\hline \multicolumn{2}{|c|}{ Medicine school } & 0.089 & 0.117 & $0.760^{* *}$ & 0.329 \\
\hline \multicolumn{2}{|c|}{ University size } & $0.238^{* * * *}$ & 0.142 & $0.638^{* * *}$ & 0.246 \\
\hline \multicolumn{2}{|c|}{ Intercept } & $-3.456^{* *}$ & 1.206 & $-11.280^{* * *}$ & 2.379 \\
\hline \multicolumn{2}{|c|}{$\mathrm{F}-$ test } & $63.300^{* * *}$ & & & \\
\hline \multicolumn{2}{|c|}{ R squared } & 0.890 & & & \\
\hline \multicolumn{2}{|l|}{ RMSE } & 0.268 & & & \\
\hline \multicolumn{2}{|c|}{ Log likelihood } & & & -109.184 & \\
\hline \multicolumn{2}{|c|}{ Pseudo $\mathrm{R}^{2}$} & & & 0.190 & \\
\hline \multicolumn{2}{|c|}{ Wald chi ${ }^{2}$} & & & $112.210^{* * *}$ & \\
\hline
\end{tabular}

${ }^{\mathrm{a}}$ Robust standard errors adjusted by heteroskedasticity.

${ }^{*, * *, * * *}$ Significance at the $10 \%, 5 \%$, and $1 \%$, respectively.

${ }^{* * * *}$ Significant at the $10 \%$ without robust standard errors treatment. 
Table 2. Results of the cluster analysis (means and standard errors).

\begin{tabular}{|c|c|c|c|c|}
\hline Variables & Cluster $1^{a}$ & Cluster 2 & Cluster 3 & Cluster 4 \\
\hline \multirow[t]{2}{*}{ Papers (2006-10) } & $3,139.000$ & $1,814.048$ & $5,046.444$ & $7,663.143$ \\
\hline & $(1,264.350)$ & $(770.190)$ & $(2,242.783)$ & $(3,367.826)$ \\
\hline \multirow[t]{2}{*}{ Patents Granted (2006-10) } & 21.500 & 17.143 & 56.333 & 44.000 \\
\hline & $(16.031)$ & (12.924) & $(41.566)$ & $(19.374)$ \\
\hline \multirow[t]{2}{*}{ TTO staff in IPR tasks (\%) } & 5.6 & 8.0 & 10.3 & 7.2 \\
\hline & $(0.036)$ & $(0.060)$ & $(0.084)$ & $(0.047)$ \\
\hline \multirow[t]{2}{*}{ Papers Q1 (\%) } & 46.0 & 45.6 & 46.4 & 45.4 \\
\hline & $(0.072)$ & $(0.055)$ & $(0.034)$ & $(0.039)$ \\
\hline \multirow[t]{2}{*}{ R\&D income } & $25,559.34$ & $15,653.84$ & $62,626.99$ & $53,206.10$ \\
\hline & $(17,109.62)$ & $(8,535.591)$ & $(28,828.61)$ & $(18,390.86)$ \\
\hline \multirow[t]{2}{*}{ Budget TTO } & 208.770 & $124,733.4$ & $333,190.4$ & $405,770.3$ \\
\hline & $(86.072)$ & $(42,809.59)$ & $(103,834.6)$ & $(131,779.8)$ \\
\hline \multirow[t]{2}{*}{ Age HEI } & 178.000 & 20.667 & 36.889 & 554.857 \\
\hline & $(208.040)$ & $(7.052)$ & $(6.972)$ & (114.596) \\
\hline \multirow[t]{2}{*}{ Age TTO } & 19.250 & 16.048 & 19.889 & 20.857 \\
\hline & $(3.304)$ & $(3.735)$ & $(2.804)$ & $(2.268)$ \\
\hline \multirow[t]{2}{*}{ Polytechnic university } & 0 & 0 & 0.333 & 0 \\
\hline & $(0)$ & $(0)$ & $(0.500)$ & $(0)$ \\
\hline \multirow[t]{2}{*}{ Medicine school } & 1 & 0.762 & 0.667 & 1 \\
\hline & $(0)$ & $(0.436)$ & $(0.500)$ & $(0)$ \\
\hline \multirow[t]{2}{*}{ University size } & $348,801.3$ & $170,112.6$ & $373,016.3$ & $511,222.5$ \\
\hline & $(170,995.00)$ & $(81,984.8)$ & $(128,049.7)$ & $(199,756.6)$ \\
\hline Universities & 4 & 21 & 9 & 7 \\
\hline
\end{tabular}

Standard error in brackets.

${ }^{\mathrm{a}}$ Cluster 1, after excluding Universidad de Salamanca. 